\title{
Aspectos de la Poesía Israelí \\ Contemporánea
}

Por MOSHE LAZAR

No tengo la intención ni la presunción de presentar, en el marco de esta exposición, un panorama completo de la poesía israelí contemporánea. Alpresentar aquí ante ustedes una serie de nombres y de fechas, o el cítar los títulos de numerosas compilaciones poéticas, demostraría, tal vez, que conozco en algo este capítulo de nuestianhisteria literaria, pero les haría apenas sentir la palpitación viviente de da durica hebraica moderna. Parafraseando más o menos un pensamiento de García Lorca, diría: los hechos y las fechas, las causas y las razones que conciernen a una obra poética, puede ser útil saberlas, pero no hay que repetirlas. Mi propósito es modesto: presentar aquí, ante ustedes, algunas voces del actual mundo poético de Israel, hacerles sentir la atmósfera de esta poesía, que se inspira en la lengua e imágenes de la Biblia, absorbiendo al mismo tiempo las resonancias de la poesía universal contemporánea.

La elección de los poetas y sus poemas será, como toda elección auténtica, subjetiva y personal. Y como no distribuyo "Premios a la poesía", no estoy obligado a justificarla. Las voces de los poetas que tendrán ocasión de escuchar aquí no representan todas las voces importantes de la poesía israelí moderna, ni tampoco son las que yo, personalmente, amo, sino una variedad lo suficientemente amplia como para no ser arbitrario ni injusto. En cuanto a la calidad de esta poesía, ustedes serán los jueces, teniendo en cuenta que oyen una traducción y no la tonalidad del original. Las traducciones, e incluso las me- 
jores - dice nuestra poetisa Lea Goldberg — son como una declaración de amor por teléfono: se oye la voz del amado sin verle la cara. Quisiera esperar que esta voz, por lo menos, llegara hasta ustedes.

Cuatro generaciones de poetas compusieron sus obras dentro de los límites de lo que llamaremos "la poesía hebraica contemporánea". No son éstas generaciones biológicas, sino espirituales, sin punto de identificación con ninguna escuela poética determinada. En el interior de cada uno de estos grupos, los poetas se distinguen unos de otros por sus personalidades netamente definidas y por sus estilos individuales. En cuanto a los temas tratados, estos son a veces comunes a alguno de los grupos, y a veces a poetas de diferentes grupos. Si, por ejemplo, la situación trágica de los judíos en la Diáspora y el sueño de la redención constituyen el tema de numerosos poetas del primer grupo, los de la segunda generación cantan ya el entusiasmo que procura la tierra prometida y recientemente recobrada, la regeneración espiritual y casi mística de un pueblo de pioneros, en tanto que la tercera ve nacer poetas que no han conocido la Diáspora, o que la han conocìdo muy poco, que han escrito sus poemas entre combate y combate durante la Guerra de la Independencia y para quienes la Tierra de Israel no es ya una realidad soñada o mística, sing una presencia cotidiana, física, dura, con la cual habran firmado un pacto de sangre. Los poetas más jóvenes - los de la generación reciente- han crecido sobre este mismo suelo pero en otro ambiente, posterior al sacrificio y al día solemne; sus problemas son otros, y ellos están más atentos al malestar existencial, cuyo eco les llegaba a través de las obras de la literatura universal.

Si tomamos la Biblia con todo lo que ésta incluye, a más de su mensaje religioso y espiritual, en imágenes, expresiones, escenas y personajes, veremos que ella es el punto de partida del que proceden todos los poetas de las diferentes generaciones, los que, después de recorrer las sinuosidades y rodeos de sus caminos individuales, vuelven a encontrarse, muy a menudo, en la misma encrucijada, junto al mismo manantial. Pero, también aquí hay que cuidarse de generalizaciones apresuradas. La expresión bíblica no emite el mismo sonido en las obras de todos los poetas. El héroe bíblico sufre constantes metamórfosis. La imagen bíblica puede ser copiada, creada nuevamente, desfigurada, intensificada, caricaturizada, todo según la personalidad e intenciones de tal o cual poeta. 
Desde las grandes figuras poéticas de la primera generación - Jayim Najman Bialik, Saúl Tchernijovsky y Zalman Schneour-, pasando por las de la segunda -Abraham Shlonsky, Nathan Alterman, Lea Goldberg y Uri Zvi Grinberg -hasta los representantes de la joven poesía - Amir Guilboa, Jayim Gouri, Carmi, Amijay y otros- la lírica hebraica ha manifestado siempre una extraordinaria vitalidad, produciendo obras que, por su contenido y forma, renuevan el contacto con la tradición poética antigua: la de la Biblia y la que conociera su siglo de oro en la España e Italia medievales.

¿Qué elegir, entre toda esta riqueza, para que nuestra disertación no sea demasiado superficial? Ya que no puedo recalcar todos los temas de cada poeta, he seleccionado los diversos poemas de tal manera que puedan, en su conjunto, crear una imagen fidedigna de este renacimiento poético en lengua hebraica.

La lamentación sobre las desdichas del pueblo perseguido encuentra, en la época de los "pogroms" en Rusia, la potente pluma del Jayim Najman Blalik para expresar la impotencia de toda justicia, humana o divina, para vengar la muerte de un niño inocente:

\section{Biblioteca de Letras}

Si hay justicia, brille worarinlismorso"

Si después que sea yo raído de bajo el firmamento

brilla la justicia,

entonces sea volcado su trono para siempre

y los cielos púdranse de maldad interminable.

Pero vosotros, malhechores, seguid atropellando,

vivid entre la sangre, inocentes.

Maldito el que diga ¡venganza!

Venganza así, venganza por la sangre de un niño pequeño,

no la inventó aún Satanás.

Cale la sangre en el abismo,

cale la sangre hasta los abismos tenebrosos

y socave en la tiniebla los cimientos

podridos de la tierra.

En un poeta de la siguiente generación, Uri Zvi Grinberg, encontramos, en la compilación "Vías del río", la expresión poética más potente que se haya dado hasta el presente al exterminio de seis millones de judíos por los nazis. Son los "lamentos 
de Jeremías" de nuestra época. Los largos poemas de este poeta adoptan el estilo patético, el lenguaje recio, el ritmo de la prosa fulgurante como un relámpago de los Profetas de la Biblia. Escuchen, por ejemplo, la estructura monumental de esta escena apocalíptica:

\section{LA COLINA DE CADAVERES EN LA NIEVE}

Cuando sacaron a mi padre para la colina de cadáveres, en los campos /extranjeros nevaclos, aulló el general alemán: a desvestirse. Y mi padre comprendió bien la

Se quitó mi padre el abrigo y los pantalones /sentencia.

como si se quitase la realidad del mundo, se arrancó los zapatos como para el duelo de la tarde de $\mathrm{Ab}$, y se quedó en su ropa blanca, con las medias.

¿Qué había más desnudo que su desnudez bajo la bóveda del cielo y en el campo nevado, aquel día, en el mundo? Nunca se había encontrado con tanta desnudez bajo la bóveda del cielo, bajo el gorrito negro del cráneō,

a no ser por las noches al pie de la cama, a no ser en la casa de baños, al entrar a sumergirse, que entonces sóle se quitabåilalinopaablañeardas medias y el gorro y no "Jorge Puccinelli Confiniraba

los pudores de su carne hasta que las aguas la cubrían por una y otra como quien desciende a adorar en lo profundo. /parte:

Pero cuando vio el general que mi padre estaba aun en ropa blanca, con el gorrito en la cabeza, aquel malvado le asestó un golpe entre las paletillas con su arma fría, y mi padre tosió y cayó de cara, como delante de Dios, se postró profundamente hasta lo más hondo de la vida, y no se levantó: emitió un quejido, como conclusión de la súplica postrera, después de lo cual nada existió fuera de los cielos nublados y de la colina /de cadáveres,

con la sangre que salía por la boca del pulmón aplastado. $\mathrm{Y}$ al ver el general que mi padre no se levantaba, metió la puntera de su bota negra por debajo del vientre del padre venerable, y le sacudió y le puso boca arriba, y parecía que en su rostro la tierra pagana le pegaba puntapiés.

Y con el anochecer brotaron las estrellas y crecía la colina de cadáveres /en el campo, 
y la nieve caía en la noche con una abundancia cruelmente blanda.

Así lo quería Dios. Se notaba que había Dios, aunque era el Dios de los paganos. No hay Dios para Israel.

Sólo la nieve fue testigo. Bajaba con abundancia cruel.

Acertó a pasar por aquel sitio, Rabí Urí de Strelisk, el Serafín, el abuelo, $\sin$ que se oyera ningún ruido de pasos ni respiración en el aire.

Abrió su boca y dijo susurrando: Rabí Jayim, hijo de Rabí Isaac, nieto /mío,

cuerpo que era un arpa de las oraciones de Israel, boca que derramaba consuelo al afligido, ¿cómo te cubre la nieve en el campo de los paganos infinito?

¿Dónde fueron tus oraciones, nieto mío?

¿Dónde fueron las mías?

¿A qué región del mundo?

De la colina de cadáveres rebulló y se deslizó

mi primo Samuel, a quien llamaban Samuelito. Rebulló

y se deslizó a los pies del abuelo Rabí Urí de Strelisk,

el Serafín. Gimoteó como un chiquillo y

no abrió sus ojos porque no podia. Palpó

con la palma de sus manos pequeñas toszapatos del abuelo, y el abuelo se inclinó hacia él ỳ le besó en la frente y le dijo:

bebe mio,

criatura santa.

Contestó el hijo de mi hermano uveneriable eld, chiquillo

de nombre Samuel, a quien llamaban por cariño Samuelito:

Abuelo, abuelo, ¿por qué no viniste antes con multitud

de serafines y de ángeles?

Abuelo, abuelo, ¿dónde está el Dios de los judíos?

Y calló el niño y quedó echado

a los pies del abuelo Rabí Urí, que se había retrasado con sus lámparas, que no había traído una muchedumbre de ángeles a nuestra casa como /escudo.

Y Rabí Urí de Strelisk, el Serafín, estaba de rodillas helándose en el Y la nieve caía, caía. /campo extranjero.

La guerra, todas las guerras de nuestro siglo, han marcado con profundas heridas el corazón de nuestros poetas. Los estigmas de estas guerras y la angustia ante guerras futuras constitituyen el tema de numerosos poemas. Así, por ejemplo, en la obra de los siguientes poetas, todos de una edad que oscila entre los cuarenta y los cincuenta años. En primer lugar, este soneto de Yehudah Amijay: 
Mi padre estuvo cuatro años en la guerra de los otros y no odió, no amó a sus enemigos, y yo sé que allí me edificaba día a día con sosiegos

muy escasos, que entre el humo y las bombas, recogía y guardaba en su mochila raída con las sobras del bizcocho maternal endurecido.

En sus ojos reunía muertos sin nombre, muchos muertos reunió por mi causa, para que yo los conociera en su mirada y los amase,

y no muriese como ellos en el terror.

Llenó los ojos de ellos pero se equivocó.

a todas mis guerras yo salgo.

En un estilo diferente, con una insinuación de ironía para intensificar su horror a la guerra y su duelo personal, he aquí la voz de Amir GuilboaBiblioteca de Letras "Jorge Puccinelli Converso"

\section{HERMANO CALLABA}

Mi hermano volvió del campo con la ropa gris.

Yo temía que mi sueño tal vez me engañara y empecé rápido a contar sus heridas.

Después hurgué en la guerrera, en los bolsillos y encontré una venda que secaba su mancha. $\mathrm{Y}$ en una postal arrugada, el nombre de ella. bajo un dibujo de amapolas. Y mi hermano callaba.

Entonces desaté un envoltorio y fui sacando sus cosas, recuerdo tras recuerdo. Bravo, hermano mío, qué héroe. Mira, encontré tus laureadas. Bravo, hermarto mío, qué héroe. 
Cantaré con orgullo a tu nombre.

Y mi hermano callaba.

Y mi hermano callaba.

Y su sangre clama desde la tierra.

Parodiando la descripción bíblica de la creación del mundo, Aharón Amir representa ante sí mismo una farsa imaginaria, a fin de ocultar mejor el sentimiento trágico de la vida:

\section{CUANDO CONCLUYA TODO}

Cuando concluya todo habrá que empezar otra vez desde el princıpio,

y cuando la humareda de la nube de musgo se disuelva y se limpie la tierra y sus hombres de la contaminación radiactiva en un plazo, en equis plazos y medio, se empezará otra vez desde el principio quizás en la isla de Tasmania,quizás en tierras del Congo o en la cumbre del Ararat, quizás aquí, entre el Pishón y el-Guijón, se trazará precisa la línea entre la tierra y los cielos. entre las aguas de arriba "Đordas de elabajorso"

Sólo que esta vez no vendré yo en el sexto día, sino que lo veré todo desde el principio, esta vez, y el Creador será a mi semejanza e imagen,

y le marcaré la obra esta vez, $y$ el orden de crear,

y con mis propias manos tomaré a Eva.

a Eva la nueva

de una de mis costillas.

$\mathrm{Y}$ nos cubriremos al punto con las hojas de higuera, desde la cabeza al tobillo, y no iremos por el Paraíso de merienda, ni nos entretenderemos con Dios o la serpiente, sino que nos pondremos al punto a la tarea penosa, y quizás esto marche, esta vez.

Finalmente, estos versos de Ben-Zion Tomer, que expresan con intensidad el malestar y el sentimiento de culpabilidad por haber sobrevivido, en tanto que los demás han muerto (este motivo aparece en la obra de muchos poetas): 
Yo no soy culpable, padre, soy la flor entre las ruinas, tu casa naufragó, padre, yo solo he sobrevivido, una isla.

Es terrible, padre, ser una flor entre las ruinas, ser una isla en la sangre.

Si al menos fuera culpable, padre.

Náufrago de múltiples muertes, con las manos vacias y el corazón desolado, el pueblo judío poseía aún dos tesoros imperecederos, dos fuentes de vida eterna: la Biblia y la tierra prometida, que nunca los habían abañdonado, impregnando sus plegarias y sus sueños. Y cuando este pueblo volvió a su tierra, sus poetas tuvieron la impresión de un día para otro, de no haberla dejado nunca: el paisaje era familiar, los nombres de los valles y las colinas volvieron a la memoria, las figuras bíblicas resucitaban en las calles de Jerusalén y Tel Aviv. Como después de una larga noche, como después de las angustias de una pesadilla, todos estaban alli, reales y vivientes, en el momento del despertar: Caín y Abel, Moisés y Míriam, Saúl y David. La Biblia no era más un álbum de recuerdos, la crónica de un pasado glorioso, sino la "jormagena divientes de un presente eterno.

Aun si han cambiado un poco la voz o la vestimenta, podrán reconocerlos sin esfuerzo en los poemas que les presentaré a continuación.

La poetisa Rajel, muerta en la juventud, a orillas del Mar de Tiberiades, canta en estos versos a la mujer de Jacob, con la que se identifica en el alma y en el nombre:

\section{$R A Q U E L$}

Su sangre corre por mi sangre,

su voz en mí canta,

Raquel, la pastora del rebaño de Labán,

Raquel, madre de madres.

Por eso la casa me es estrecha

y la ciudà extraña, porque el viento del desierto con su velo me llama. 
Por eso con tal seguridad me pongo en camino, porque guardan mis pies tantos recuerdos de antiguo, de antiguo.

Los hermanos enemigos, el inocente y el asesino, reviven el instante que precedió al primer crimen, cara a cara y teniendo sólo a Dios por testigo, en estos dos poemas de Abraham Shlonsky:

\section{$L A B R A D O R$}

Un camello y la arada. El filo de la reja que terrón y terrón separa con fatiga. Nunca fuera el mundo tan uno.

Toda la eternidad abrazada en un instante.

Aquí, un barrunto de crimen, la reja que se clava.

Aquí Caín que hiende da unidad del terrón.

Nunca fuera tan corta la chistancia

entre un hombre,

un camello

y el cielo

Biblioteca de Letras

"Jorge Puccinelli Converso"

$P A S T O R$

Esta vastedad que dilata sus narices.

Esta altura, anhelosa de ti.

La luz que rebosa blancura de leche.

El olor de la lana.

El olor del pan.

Y a la vera del rebaño y del hombre, atenta

a los bruscos lametones en la acequia.

descalza, desnuda en sus cinco sentidos, la mañana que camina al medio día.

Mañana del Génesis. En los campos los rocíos de la hierba se evaporan. Y la humareda del estiércol.

De horizonte a horizonte: un hombre y el campo.

De horizonte a horizonte: el rebaño y Abel. 
El poeta Jayim Guri no se limita a los actos heroicos descritos en la Biblia, y donde ésta calla, él comienza su canto. El poeta sabe que Jael, al matar al general Sisara, permitió aí pueblo hebreo la victoria. Lo sabe porque el cántico de la profetisa Débora canta el elogio de esta mujer arriesgada. Pero el poeta, por un sentimiento de justicia poética y humana, ve a otra mujer, ya vieja; la madre de Sisara, esperando el imposible regreso de su hijo:

\section{SU MADRE}

Hace años, al final del cántico de Débora, oí el carro silencioso de Sisara que tardaba en llegar.

Vi a la madre de Sisara transparentarse en la ventana, una mujer con hebras de plata en el cabello.

"Un botín de colores boțdados, calados polícromos para eh cuello de los guerreros", veían las doncellas, justo cuando él yacía en la tienda adormecido, con manos vacías de todo, en la harbilla un rastra de leche mantequilla y sangre. Caballos y carros naicompieroncel silencio.

Las doncellas se callaron una a una:

mi silencio y el suyo se tocaban.

Poco después se puso el sol.

Poco después se fue el crepúsculo.

Cuarenta años estuvo en paz la tierra. Cuarenta años no galoparon los caballos, no clavaron los muertos el vidrio

Pero ella murió a poco de la muerte de su hijo. /de sus ojos.

La melancólica imagen del primer rey de Israel, Saúl, frecuenta desde siempre la imaginación de poetas y pintores, por lo que no es raro verla resucitar en la pluma de numerosos poetas israelíes. Citaremos tres interpretaciones, que evocan bajo diferentes aspectos a este rey desventurado, obsesionado hasta la locura, y calmado por momentos bajo la influencia del arpa de David.

En primer lugar, el poema de Dan Paguis: 


\section{ULTIMA ORACION DE SAUL}

Dios mío, como un buey de labranza

fui fornido entre todas tus piedras.

Y callado bajo el yugo de tus truenos.

Pero se me hizo el silencio Satanás.

Estoy rendido. Retiraste dẽ mis hombros

el manto real y en terrones inocentes

sumergiste tu ejército roto.

Oh Dios mío, Dios mío, el elevado, el dominante,

el que baja a mi alma como la tempestad al campo.

Aquí tienes la mies. Amén.

En un estilo más modernista, Nathan Zakh nos hace sentir la indefinible música del arpa de David:

DESCRIPCION EXACTA DE LA MUSICA QUE OIA SAUL EN

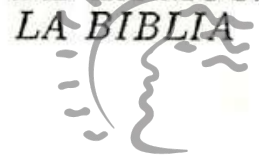

Saúl oye música.

Saúl oye.

¿Qué música oyeB\$aúl?teca de Letras

Saúl oye música "Jorge Puccinelli Converso»

y se alivia.

Saúl oye música.

Música oye Saúl.

Y los hombres a su lado no están más que

velados, todo el pueblo mudo.

Porque Saúl oye música.

¿Será esta la música

que Saúl habría de oir

en un momento tal?

Sí, esta es la música

que Saúl habría de oir

en un momento tal

porque no hay otra ahora.

y tal vez no la habrá

hasta el monte Guilboa.

Finalmente, pasado y presente se confunden en el poema de Yehudah Amijay, que confronta sus propia lasitud con el fin trágico del rey: 
Le daban un dedo y agarraba la mano, me daban la mano, ni el meñique tomaba.

Andaba mi corazón por los primeros ejercicios y abatía él ya toros.

Mi pulso latía cual goteo de un grifo, el suyo golpeaba como un mazo la cantera.

Era mi hermano mayor, yo gastaba sus ropas.

Salió a buscar las asnas

- que luego encontré yo -

y le ungieron por rey.

Estoy cansado, mi lecho es mi reino.

En una silla cuelgó la ropa de mañana.

El colgó su reino e Puccinelli Converso en un marco dorado de rencor, en la pared del cielo.

Mis brazos son cortos, escasos aún para liar un saco.

Los suyos eran cadenas de muelle para descargar más allá del tiempo.

$\mathrm{El}$ es un rey muerto.

Yo un hombre cansado.

Una manera más compleja de tratar el motivo bíblico es ilustrada por el poema "Míriam" de Carmi, que emplea el versículo bíblico como soporte temático y musical de una experiencia personal e íntima: 


\section{$M I R I A M$}

E hizo Moisés una serpiente de bronce

Míriam, Míriam bailarina, hermana del mar y del golpe del tambor.

Sube a mi como una fuente viva, enséñame a bendecir el milagro

y la luz del amanecer

$\mathrm{y}$ el temor de mis ojos.

Y la colocó en el mástil

Míriam, Míriam profetiza, hermana y cómplice, flor y serpiente, enséñame a ocultarme,

a revelarme como una víbora venenosa

y extender las manos

hacia inmaculados altares.

Si una serpiente mordtera al hombre

Míriam, Míriam leprosa, hermana para el escarnio y la vergüenza, enséñameBâbiortarmle comosun muerto

fuera del campamentó,onverso"

enséñame a decir la verdad

y a elevar los ojos.

$Y$ miró la serpiente de bronce y vivió.

Quisiera citar otro poema de este poeta - Carmi- en el que expresa veladamente el momento en que la inspiración poética choca con la realidad; se basa, para la construcción de sus imágenes, en determinados versículos de la liturgia judía, imposibles de transmitir por medio de uma traducción. Es necesario conocer la liturgia para poder apreciar en qué medida enriquece los versos por asociación de imágenes.

\section{AL GRANADO}

Vete, vete de aquí, vete a otros ojos.

Ya escribí de ti ayer. 


\author{
Dije verde \\ a tus ramas inclinadas al viento. \\ y rojo, rojo, rojo, \\ a las gotas de tu fruta. \\ Grité luz a tu raíz \\ húmeda, oscura y obstinada. \\ Ahora ya no existes. \\ Ahora me tapas el día \\ y la luna que aún no ha subido.
}

Ven tú.

(De ti escribí antes de ayer,

tu recuerdo fresco

quema como ortigas todavía mis manos).

Ven y mira este extraño granado;

su sangre está en mi alma, en mi cabeza, en mis manos,

y él aún sigue plantado en su lugar.

Quisiera hacerles oir la voz particular de dos poetas, cuyas obras son leídas por un gran público desde hace más de veinte años. Se trata de Nathan Alterman, cabecilla de la poesía hebraica contemporánea, y de la poetisa Lea Goldberg, la voz femenina más sensible de la lírica israelí.

\title{
Biblioteca de Letras
}

He aqui este poema de Afterinanner construído como una balada trágica, que trata de un niño abandonado por su madre:

\section{EL EXPOSITO}

Junto a un cerco me dejó mi madre, de espaldas, con la cara arrugada y tranquilo.

Yo la miré descle abajo, como descle el fondo de una fuente, hasta que se escapó como quien huye de una batalla.

Yo la miré desde abajo, como desde el fondo de una fuente.

La luna se levantaba sobre nosotros como una vela.

Antes de que aclarase el alba, aquella noche, me levanté despacio porque llegó el tiempo y volví a casa de mi madre como una pelota que rueda regresando a los pies que la impulsaron.

$\mathrm{Y}$ volví a casa de mi madre como una pelota que rueda

y me abracé a su cuello con manos de sombra. 
De su cuello, a la vista de Dios, me arrancó como a una sanguijuela.

Pero, cuando volvió la noche, volví a ella como ayer, y esto era para nosotros una ley:

cuando volvió la noche, volví a ella como ayer,

y ella todas las noches retomaba su yugo.

Las puertas de su sueño me están ampliamente abiertas y no hay nadie más que yo en su sueño, porque quedó el amor entre nuestras almas tenso como un arco, desde el día en que nací.

Porque quedó el amor entre nuestras almas tenso desde siempre, hasta siempre.

Y, por eso, hasta lo último Dios no me apartó del doliente corazón de mi madre

y a mí, que me arrancaron de su pecho antes de tiempo, no me aparté, sin embargo, de su lado.

Y a mí que me arrancaron de su pecho antes de tiempo, entré en su casa y cerré su puerta.

Ella envejeció en mi prisión, se encogió y su cara se arrugó como la mía.

Entonces, mis manitas la vistieron de blanco como una madre viste a su,niño.

Entonces, mis manitas ja yistieron det blanco

y la llevé sin decirle adónde.

La dejé al lado del cerco, de espaldas, vigilante y tranquila

y me miró riéndose, como desde el fondo de una fuente. y supimos que habíamos finalizado la batalla.

Y me miró riéndose, como desde el fondo de una fuente.

La luna se levantaba sobre nosotros como una vela.

Citaré dos poemas cortos de Lea Goldberg, extraídos de una serie intitulada "Canciones del torrente":

\section{EL TORRENTE CANTA A LA PIEDRA}

He besado la piedra, sumida en su frío sueño, pues yo soy el cántico y ella es el silencio, ella es el enigma y yo soy quien lo propone, pero los dos provenimos de la misma perennidad. 
He besado la piedra, su carne desnuda, siendo ella colmada de fe y yo el traidor, yo soy el que muda y pasa, mas ella permanece, ella guarda los secretos de la creación, mas yo los descubro.

Y me consta que paso junto a un corazón apacible: yo soy el cantor y ella, la piedra, el mundo sensible.

\section{LA MUCHACHA CANTA AL TORRENTE}

¿A dónde se lleva la corriente mi pequeña faz? ¿Por qué hiere el fulgor de mi mirada? Mi casa queda alejada en el bosque de pinos ¡Melancólico es el mundo de mis pinos!

Me sedujo el torrente con su sonora canción. alegremente cantaba y llamaba mi nombre, fui hacia él guiándome por sus claros ecos, y de este modo abandoné la casa de mi madre.

Y yo era su única hija, tierna de años, mientras que el torrente mostrábase altanero ¿Adónde se lleva él mî pequeño rostro? ¿Por qué hiere felfulgoradee mitmirada? "Jorge Puccinelli Converso"

Habiendo comenzado esta exposición con la voz de un gran poeta de la primera generación, Jayím Najman Bialik, quisiera terminar con un poema de su contemporáneo, Saúl Tchernijovsky, optimista y con la mirada tendida al Forvenir, de gran influencia sobre la joven poesía.

\section{YO CREO}

Sonríe, mujer mía, sonríe ante los sueños

que yo, constante soñador, te refiero; sonríe, porque aún creo en el hombre, porque aún creo en ti.

Porque aún mi alma ansía la libertad, pues no la he vendido al becerro de oro, porque aún creo en el hombre, en su espíritu bravío y ardiente. 
Su espíritu sacudirá las vanas cadenas y elevará al hombre a las altas cumbres, el trabajador no morirá de hambre:

libertad para el alma, y pan para el pobre.

Sonríe, pues aún creo en la amıstad, aún creo que encontraré un corazón, un corazón cuyas esperanzas serán igual que las mías que sentirá mi dicha y comprenderá mi dolor.

Quiero creer aún en el futuro, aunque se difiera el día propicio, pero ciertamente vendrá un mensaje de paz y de bendición de parte de un pueblo para otro

Entonces volverá a renacer mi pueblo y en la tierra se levantará una generación que romperá las coyundas de hierro que nos oprimían y cara a cara contemplaremos el sol.

Vivirá, amará y actuará una generación sobre la tierra

- no en el futuro, incierto, on los cielos con una vida espiritual incontenible.

\section{Biblioteca de Letras}

Entonces el poeta cantará lun eánticorsuluevo dedicado a la belleza. y su corazón sensible jubilará, y para él, para este joven. flores cogeréis de sobre mi tumba y una corona le tejeréis.

Vuelto al punto de partida, el círculo queda cerrado. La breve antología que traté de presentarles está lejos de ser completa, y no refleja toda la variedad de temas y de estilos. Pero espero que, de todos modos, habrá mostrado una de las facetas más importantes de la poesía hebraica en proceso de resurrección. Si logré hacerles sentir, aunque sólo no sea en algo, el timbre peculiar de su voz, me sentiré satisfecho. Y estoy seguro que las musas de la lírica no me reprocharán el que haya dejado de hablar a los peetas, en lugar de citar fechas y títulos, ya que ellas nunca han amado los rótulos y catálogos de la historia literaria. 